\title{
Reflections on Water: Architectural Manifestations in the Historic and Cultural Quarter along Lake Pichola in Udaipur
}

\author{
S Samant \\ Department of the Built Environment, University of Nottingham, UK \\ E-mail: swinal.samant@nottingham.ac.uk
}

This research was supported by INTACH (UK) Travel Grant

\begin{abstract}
The aim of this paper is to undertake a critical appreciation of the historic cultural quarter along the eastern edge of Lake Pichola in Udaipur, which is a result of its unique context with the objective of understanding the forces that underpin this development, examine its existing state, and highlight key concerns. The main issues that were highlighted include preservation of existing traditions, conservation and adaptive reuse of historic structures, sensitive and participatory planning and design, formalising of street activities, provision of infrastructure, and administrative structures to deliver the project, and organisation of awareness programs for the local community.

The aim of this study is to develop a critical appreciation of the historic core and cultural quarter along the eastern edge of Lake Pichola in Udaipur, which is a result of its unique climatic, social, and topographical context, to chart the changes to this context, to draw attention to past patterns of growth. The objective is also to understand the forces that have influenced and underpin this development, examine its existing state and highlight key concerns. The study is limited to the historic core along the waterfront and its related structures along the eastern bank of Lake Pichola in Udaipur. The study demonstrated that the historic core along the lake front is a result of evolution that has been guided by dominant determinants such as its socio-economic hierarchy/structure, political, cultural, and religious factors, climate, availability of materials and technology. The overall form, settlement pattern and the massing of buildings in Udaipur are dominated by its physical attributes and in consonance with the topography and landscape, and ordered by the generative force of its land form and the lake. It is, however, subject to severe developmental and environmental pressures as a result of intense tourism related and commercial activities, unwarranted and haphazard building activities, continuous neglect of residential properties, some of the historic fabric and surviving artefacts, and poor infrastructure. If this trend were to continue, the problems will intensify manifold causing serious threat to this valuable environment, its urban spaces and exquisite edifices. Preservation of this waterfront, which plays a decisive role in solving critical urban, social and economic problems in this city, is vital. The main issues identified for consideration in this context were preservation of existing traditions, conservation of historic structures and adaptive reuse of buildings, sensitive and participatory planning and design, formalising of street activities, provision of infrastructure and administrative structures to deliver the project, and creation of awareness and understanding amongst the local community.
\end{abstract}

Keywords: Waterfronts, Historic architecture, Planning and design

\section{Background}

Udaipur known as the city of lakes is in a bowl-shaped basin located on the eastern flank of the hilly Aravalli ranges in Southern Rajasthan (Western India) at 1893 feet above the mean sea level. Udaipur's distinctive features of the lakes, its geographically secluded position due to the natural enclosure formed by the surrounding hills and the altitude, and its rugged terrain created favourable site conditions for the medieval settlement in terms of natural defence, micro-climate and opportunities to develop itself. Hence Maharana Udaisingh moved from the old capital of Chittorgarh and founded Udaipur in 1559 A.D. The lakes in Udaipur form important infrastructure, provide visual structure and orientation cues, and lend visual/ psychological relief in its hot dry environment (Naik, 1997).

Cues from the topography led to the positioning of the main city-palace of Udaipur, the seat of political power, at the highest level on a rock mass that overlooked lake Pichola on its eastern edge (Figure 1), in the South-West direction of the city. Religion was the other powerful force that was physically manifested in Jagdish Temple built further down from the palace on a large mound (Naik, 1997). With the appearance of the lake and the palace which was the major controlling element of the city, by the end of the $16^{\text {th }}$ century, a cluster of population grew around the palace in accordance with the need of the ruling family and people in general, and the religious and aesthetic needs of the time. The courtiers and warriors were the first to move to the new settlement and they occupied the area close to the north of the palace. Over a period of time, different communities built houses on the sloping terrain forming their own community groups based on their caste, religion, social status or occupation. Over time, the residential fabric expanded to either sides of the lake with several new additions and insertions, a process that still continues. This growth gradually led to the development of a township which was 
structured in such a way that all major streets led to the palace complex and that it could be located from any point in the city due to its prominent higher location. Over time, Udaipur has survived diverse and complex pressures of socio-economic, commercial and industrial growth and today lends itself as a very important tourist city with a peculiar charm, significant history, rich ecology and outstanding architectural and cultural heritage.

The heritage fabric of the city presents an excellent example of harmony between its natural elements (water and water reservoirs, mountains, dense forests, fauna in the wild and perennial rivers in Aravalli hill ranges, abundant natural landscapes-green open spaces, gardens and wildlife) and man-made elements (lakes, lakefronts, gardens, streets and squares, fort walls, historic monuments such as the forts, the gates ('pols'), palace complex, havelis, pavilions, historic temples and religious structures, the ruins and archaeological heritage, the streets and streetscapes and clock tower, the community structures and old residences and the water reservoirs). Water is important to the life and culture of Rajasthan and has led to rich practices of water harvesting and water storage/conservation reflected in the development of considerable variations in the forms of water structures Ghats, deep stepped basins, step wells and baories. Amongst Living Cultural heritage, the performing and visual arts including painting and sculpture, folk, tribal art and handicrafts are significant. This unique environment along with the Rajasthan pageantry of colour, festivities and traditional way of life accumulate to become the incredibly rich heritage that is "Udaipur". Despite its growth from a small princely town to an important tourist destination, it has retained the hierarchical relationship between the monarchy and the people. Its heritage is very much a part of its daily life and constitutes the Rajasthan pageantry of bright and colourful costumes, festivals and historic fine arts.

\section{Aims and Objectives}

The aim of this study is to develop an appreciation of the historic core along the eastern edge of Lake Pichola in Udaipur, to chart the changes to this context, to draw attention to past patterns and to learn from them in the hope of influencing future developments. The objective is also to understand the forces that have influenced and underpinned this development, examine its existing state and highlight key concerns.

The research is limited to the historic core along the waterfront and its related structures along the eastern bank of Lake Pichola in Udaipur. Field survey by the author comprised of detailed observations, examination and documentation of its physical aspects, activity patterns and environmental conditions. Primary research involved data collection and survey of literature; text, data, maps and drawings. Secondary Research will include research documentation and collation, and developing an understanding of the research material. An in-depth analysis and interpretation of the physical aspects of the historic eastern edge of Lake Pichola was undertaken to understand the overall architectural arrangement and its constituent parts, their uses and meanings in this context. The historic core was examined in terms of its built form, approach routes, street layouts, land use, massing and overall organization. Tertiary research entailed formulating a critical appraisal of the environment and offering critical interpretation, informed direction and arguments.

\section{Findings}

\subsection{Water and Architecture in Udaipur}

Giving an account of the procession of Udaipur, Col. James Tod remarked: "A more imposing and exhilarating sight cannot be imagined than the entire population of the city thus assembled for the purpose of rejoicing the countenance of every individual from the Prince to the peasant, dressed in smiles. Carry the eye to heaven and it rests on a sky without a cloud; below is a magnificent lake, the even surface of blue waters broken by palaces of marbles, whose arched piazzas are seen through the foliage of orange grove plantain and tamarind; while the vision is bounded by noble mountains, their peaks towering over each other and composing an immense amphitheatre" (Sen, 2000).

'Architecture, through its forms and materials, is the medium that connects or separates people and water' (Gurjar, 2004). Lake Pichola in Udaipur has been most instrumental in the development of its historic core and indeed the entire city. Historically, the lake and its geographically secluded position provided the most ideal setting for the medieval settlement in terms of natural defence and opportunities to develop itself. The lake makes profound influence on the environment by bringing about favourable changes to the micro-climate in a region where people are faced with low humidity, scorching heat and glare. Magnificent developments along the edge and within the water mass of Lake Pichola comprise of an array of diverse structures/rich collection of monuments and spaces that create a distinctive architectural composition and environment along the lake (Figure 1). The built environment demonstrates effective use of the cooling quality of water. Gurjar (2004) describes how the still lake waters generate a sense of tranquillity, repose and contemplation. In contrast, the fountains within the water mass create a sense of liveliness through their movement and in this context particularly symbolise celebration. The very sight and sound of water has the potential to provide great psychological comfort in terms of coolness. The mirrored surface of the lake reflects its surroundings in the water, increasing its visual scale and prominence. Harmony and coherence in the visual composition of the different elements that together form the lakefront is enhanced due to the reflective properties of the lake. Here, the immediacy with water is instrumental in achieving this effect. 


\subsection{Land Use}

'The entire visual order of a city is like an organism in that it is not made up of self contained parts. Interaction between the parts is continuous and essential to form a coherent and legible urban environment' (Naik, 1997). Mixed land-use along the waterfront can be classified as one which includes the palace complex, residential, commercial, religious and institutional uses. Although, the social/political climate of the formative years led to definitive patterns of land use and hierarchies in the built form, they have diluted due to changes over time. However, certain influences still remain.

\subsection{Built Form}

The historic area along Lake Pichola achieves its sense of place through its distinctive organic order, density, vernacular architecture and a built form that is recognizable as a singular entity. Built form in Udaipur is a result of evolution that has been guided by dominant determinants such as its socio-economic hierarchy/structure, political and religious factors, climate, availability of materials and technology (Jain, 1998).

The overall form, settlement pattern and the massing of buildings in Udaipur are dominated by its physical attributes and in consonance with the topography and landscape, and ordered by the generative force of its land form and the lake. The built form is also an evidence of additive layering of forms through building work that has taken place over a period of long time bringing together diverse functions and exhibiting distinctive traits/styles (Figure 2). In general, the form of the city is somewhat rectilinear and is set on the eastern slope of the hill, with the palace at the crown of the hill. Due to existing lakes and hills, growth to the south and west of the city is limited whilst with no fear of invasions the growth to the north and east is beyond the fort wall which previously controlled growth in these directions.

Large scale primary religious and administrative institutions operate at the level of the entire settlement. They stand out as main elements against the pattern of the fabric and add structure to the area. The city palace and the lake palace, icons of the city, are a representation of the power and grandeur of the bygone era. Commanding the city skyline by occupying the most secure and highest location in the city, and the palace and the fort symbolize the dominant position of the royal seat, and reflect the feudal social structure of the medieval state. The dominance of the palace complex is accentuated by its scale at the southern edge of the ghats. The scale is however, broken down with the appearance of temple shikharas and compact clustering and terraces of dwellings within the residential area towards the north (Figure 6).

The palace complex and its massive walls, havelis, temples, ghats and gates, pavilions and dwellings descend down to the water and lend a powerful linear edge to the lake on its eastern edge (Figure 3). With the exception of temples, most structures along the lake are not accessed from the lakeside. The waterfront is also lined with a number of other structures in the form of an isolated cenotaph and domed pavilions known as chattries that functioned as memorials in immediate proximity with the water. Besides, there are pavilions and palaces such as 'Jagmandir' and 'Jagnivas' that are sited within the lake. Behind this edge lies a linear yet fluid clustered organisation of dwellings along narrow streets within the dense residential fabric.

\subsection{Façade}

Continuous façade is formed along the river due to the positioning of various institutions, the relationship between them and the retaining wall. The elevation is dominated by the towering palace and fort walls but is also characterised by temple shikharas and domes over chattries and pavilions which are intricately carved with geometrical and floral patterns. The most prevalent feature in the elevations of all buildings is the cusped or peacock arch supported by balustraded and fluted columns which is characteristic of Rajput decoration. Extensive use of arched elements in the doorways and windows, use of sandstone and whitewashed walls in all the havelis, residential properties and temples help to achieve a visual coherence along the water's edge. Other repetitive elements such as recessed/projecting windows, colonnades and arcades, overhangs, brackets and balconies have been extensively deployed to provide visual link to the lake and benefit from the micro-climate it creates (Figure 3). Windows are used as decorative features particularly when used with screens to offer privacy and reduce solar gain and glare.

\subsection{Streets and Squares}

The street pattern was laid out to provide accessibility and create natural drainage on the hilly terrain. Depending on the usage, a hierarchy in the street pattern is observed in the area (Figure 7). The principle streets identified were bazaar streets with higher concentration of activities that were large in scale, connecting important nodes, punctuated by small and large chowks and landmarks, and led from city gates and culminated at the palace. The secondary streets are those that contain commercial as well as residential uses and the tertiary streets are those that lead to houses. The linear form of the street is generated by the compact terraced form of houses. Routes between nodes that are marked with prominent structures are mainly lined with shops that might be of interest to the tourists granting it a particular identity of a tourist quarter. The eastern edge of Lake Pichhola is approached via some main arteries, a series of secondary and tertiary streets and from the palace complex. Despite the immediate proximity of structures with the water, except for Gangaur Ghat there The dense built mass is made porous by narrow winding streets and squares (chowks) playing a powerful role in the visual 
structure of the area and providing relief to the compact urban form (Naik, 1997). Chowks or nodes are identified by important structures, their scale, and the activities they support. A hierarchy in the scale of the squares is evident where larger squares attract people from all over the city while the smaller or more private squares cater for a limited number of people and retain intimate scale (Jain, 1998). Jagdish chowk is the most prominent public space which is dominated by Jagdish temple and is characterised by other temples, several shops and residences.

Engendering a strong sense of community and identity, individual houses of a particular community come together to form narrow streets and at regular intervals these streets meet to form a chowk within the residential quarter. These chowks and cul-de-sacs are extremely private spaces shared only by houses within the community. This community spirit is further reinforced by the presence of private temples, sacred trees, wells and other local institutions that belong to the community and allow access solely to the residents of the community (Sen, 2000).

\subsection{Activities}

Emergence of the palace dictated activities in the past that were of political and administrative nature. Although the lake served the purpose of natural defence initially, pavilions adhering and within the watermass were later built for recreational purposes by the royals and hosted cultural performances, religious festivals and celebrations. Over time activities in the area have changed considerably as now the palace complex and the lake with its floating structures serve to be the main tourist attractions for the city. With the advent of tourism, many of the palaces, havelis and residential properties in the area have been converted into hotels (Figure 4). Ground floors in residential properties have been converted into shops that sell tourist related items (Figure 5). The local community continues to use water for daily utilitarian purposes at the ghats (Figure 6). Besides, bazaars and festivals are also celebrated on the ghats.

\subsection{Existing State}

Udaipur is a classic example of an Indian city where long decline of the waterfront environment, historic fabric and surviving artifacts is evident. This is due to several centuries of continued abuse and decay, lack of awareness/respect amongst the local community and tourists, developmental pressures, and inappropriate management of intense tourism related, religious and domestic activities. Currently, this historic precinct is under alarming pressure and if this trend were to continue, the problems will intensify manifold causing serious threat to this valuable environment, its urban spaces and exquisite edifices.

This land-water interface at Lake Pichola is one of the most important architectural assets of the city; it contributes to the image of the city, it forms a backbone to the community and is the primary economy and activity generator for the city. Many of the havelis, palaces and residential buildings that have been converted into tourist accommodation/hotels and areas in immediate proximity to them are in good order and well maintained (Figure 4). Parts of the palace have also been converted into a museum, an art gallery and shops. With the advent of tourism, commercial activities that have penetrated into the residential area and ground floor in most dwellings have been converted into shops or tourist accommodation (Figure 5). It is evident that adaptive reuse of buildings of merits and consequent investment in them has generated revenue and resulted in upkeep of properties. However, within the residential district, this change in use is fast altering the character of the streets and its traditional pattern of lifestyle.

INTACH have undertaken listing and documentation of important heritage sites and monuments in and around Udaipur on the same guidelines as those of UNESCO, some of which fall in this area. Important historic structures such as the temples, havelis and the Palace are already being conserved. However, these do not include other buildings or precincts of special cultural, traditional or socio-economic significance that are also worthy of preservation. Buildings, which are not of particular religious or historic relevance, have been ignored by the local community as well as authorities and stand in poor condition as a consequence of continued neglect. Building surfaces have not been maintained and are vulnerable to vandalism. Decorative elements of the facade have been damaged and covered with posters and graffiti, causing further clutter (Figure 7). Large scale hoardings and paintings are displayed on/across monuments, rocks, trees, parks. Due to lack of resources, living conditions of many residential properties owned and inhabited by poor families have not been maintained and are in various states of deterioration causing dilapidation (Figure 7).

Growth in tourism has led to tremendous increase in vehicular traffic causing causing air and noise pollution, and severe congestion along the access routes that were primarily designed for pedestrian use. Streets are also congested with stray animals and encroaching shopkeepers and hawkers. The area suffers from poor infrastructure and marginal inward investment resulting in lack of amenities, inadequate and highly unhygienic utility services and absence of an appropriate disposal system causing significant amount of litter and presenting a visually decaying picture (Figure 7). The general quality of the environment is very poor due to obnoxious smells from open drains and wastes of all sorts. There is a tremendous growth in motorized vehicle, physical and visual congestion. Awareness campaigns about environmental issues, sanitation and health have been conducted for the local community in the recent past. However they have failed to bring about change in peoples' attitudes.

It is evident that several new insertions and unlawful/unsafe additions and alterations that are not sympathetic to 
the scale and traditional vocabulary of the area have been built over the years. Ruins have been built over or used as a source of building materials reflecting lack of respect for the past and vision for the future. Views to historic monuments have been obscured by new structures, electric poles and wires. High rise concrete structures are jostling incongruously against old lime-mortar havelis and buildings (Figure 8).

Some examples successfully incorporate the traditional vocabulary of architecture in the new buildings; evident particularly in large hotels (Figure 9). There is evidence of use of cusped arches, balconies and whitewashed walls in new buildings in an attempt to amalgamate with the existing built context. However, the approaches adopted in the residential buildings are mere attempts at mimicking building elevations without a deeper understanding of the building type, form, orientation, internal organisation of spaces, and its implications on neighbouring properties or indeed the already stretched infrastructure. The local authority has failed to monitor such adhoc and haphazard developments. Bye-laws and guidelines with respect to heights, setback etc are not being followed.

\section{Conclusions}

Udaipur, a historic city, appears to have survived pressures of socio-economic, commercial and industrial growth and today lends itself as a very important tourist city with a peculiar charm, extensive history, and outstanding architectural and cultural heritage. The magnificent developments along the edge and within the water mass of Lake Pichola in Udaipur comprise of an array of diverse structures and spaces that create a distinctive architectural composition and environment along the lake. This unique environment along with the Rajasthan pageantry of colour, festivities and traditional way of life accumulate to become the incredibly rich heritage that is "Udaipur".

Built form in Udaipur is a result of evolution that has been guided by governing determinants such as its socio-economic hierarchy/structure and cultural context, political and religious factors, climate, availability of materials and technology. Its incremental development, overall form, settlement pattern and massing are dominated by its physical attributes and in consonance with the topography and landscape, and ordered by the generative force of its land form and the lake. 'A strong relationship with nature persists in the manner in which it structures the settlement, the linkage pattern, the positioning of institutions, religion and rituals. The unified image of the city is in effect a conglomerate of several smaller entities that are constantly changing and adapting to the needs of the time and place' (Sen, 2000). The study demonstrates that built form, organisation, skyline, density, transport networks and visual networks - paths, nodes, landmarks, edges and districts lend identity and structure to a place. Besides, local activities, beliefs, aspects of daily life also lend distinctiveness to the historic city.

Palace architecture and its related structures through their built form, internal organisation, elevations, and architectural elements demonstrate a very good understanding of their climatic and topographical context. They exhibit sophisticated understanding of the environmental and psychological benefits offered by water and natural landscape and employ them in various forms. Although the palace precinct has seen incremental process of building and growth by several rulers spanning almost five decades, they have managed to retain uniformity in design exhibiting excellent perception of aesthetics. They have successfully employed local materials, technology and, crafstmenship in making large scale buildings and small scale painstaking decorative elements.

Jain (1998) shows that in terms of housing, there is a lot to learn from Udaipur and its organisation where high residential densities have been achieved with low rise buildings. It would be beneficial where a system for housing is to be developed with an aim to retain overall harmony and order yet allow possibilities for individual variations. It is, however, subject to severe developmental and environmental pressures as a result of intense tourism related and commercial activities, unwarranted and haphazard building activities, continuous neglect of residential properties, some of the historic fabric and surviving artefacts, and poor infrastructure. If this trend were to continue, the problems will intensify manifold causing serious threat to this valuable environment, its urban spaces and exquisite edifices.

Gospodini, A. A. (2000) says that 'in the era of globalization, the relationship between urban economy and urban design, as established through out history of urban forms, is getting reversed: while for centuries the quality of urban environment has been an outcome of economic growth of cities, nowadays the quality of urban space has become prerequisite for economic development of cities; and urban design is consciously used as a means of enhancing the development prospects of cities'. Given this argument, preservation of this waterfront, which plays a decisive role in solving critical urban, social and economic problems in this city, is vital. Menon, A.G.K. (1991) rightly points out that 'it is evident that it is in such 'impossible' places, rather than in the relatively organized metropolitan cities of India, that the major problems of Indian architecture and planning manifest themselves and that these are not easily amenable to standard professionally defined interventions or the well-known solutions of urban renewal or restructuring'. Indian architects and planners look up to western ideologies and models but these must to be adapted and modified to suit the eastern, religion-oriented cities. Due to the priorities and pressures of a developing country emphasis is usually on modernization and often preservation of the vast and diverse architectural heritage and ensuring satisfactory quality of public space India 
is neglected. To save this historic lakeside, the strategy must embrace preservation of existing traditions, conservation of historic structures, sensitive and participatory planning and design, continued adaptive reuse of buildings, considerable improvement to infrastructure, appropriate re-organization of street activities, and management of building activity in the area. In this context, careful consideration of the implementation process, economic implications of a strategy and formulation of supporting administrative structures to deliver it is fundamental. Menon, A. G. K. (1991) points out that due to the inability of the municipal and government agencies to cope with layers and depths of complexities, INTACH should be involved for the redevelopment of Ujjain as they are able to cut across departments and competing interest groups to forge new links and opportunities.

Marshall, R. (2001) states 'The planning and design should not be a reflection of nostalgia of the old character or replication of the older forms but an attempt at recapturing the essence of it and finding new expression in the best of the modern design. Contextualism, in this sense, is not about the reproduction of the old but about the ability of the new to make relationships with the old'. The tradition of labour intensive building work, craft skills and decorative arts allows for the exploration and integration of ornamentation in India Architecture. A practice of imaginative reinvention and finding new ways of using the available timeless skills and technologies must be developed in new buildings.

Subsequent to Plague in 1994, the city authorities of the city of Surat forged partnerships with private sector and NGOs and with support of local population and introduction of stricter monitoring and enforcement undertook most comprehensive clean up operations which led to significant improvements in physical appearance of the city, public health and change in attitudes (Swami et al). This operation was successfully carried out without external funding or technical assistance and therefore demonstrated the capacity of local solutions and governments in developing countries in facing the challenges of rapid urbanization and improving the quality of life of all its residents. Through public-private partnership, involvement of national government, INTACH, environmental engineers, multi-disciplinary design teams and support of local population, comprehensive strategy of short term ameliorative measures as well as long term restorative measures must be adopted to accelerate the process of environmental recovery in Udaipur.

Considering the economic success enjoyed by the large hotel groups generated primarily due to their distinctive context, and given their contribution to the present environmental condition in Udaipur, funding for revitalisation of the area should also be sought from them. Besides, generation of awareness amongst the local community will be fundamental to its success.

\section{References}

Gurjar, H. (2004). Water as a Spatial Element, Diploma Dissertation, Diploma Dissertation, Ahmedabad: CEPT, India.

Gospodini, A. A. (2000). European cities in competition and the 'uses' of urban design. Journal of Urban Design. July: 18-23.

Jain, K.B. (1998). Udaipur: The City and its Elements Monograph One, School of Architecture, Ahmedabad, India.

Marshall, R. (2001). Waterfronts in Post-Industrial Cities. London: Spon Press.

Menon, A. G. K. (1991). Ujjain Heritage Zone Volume 1-Heritage Zone. New Delhi: Indian National Trust for Art and Cultural Heritage (INTACH).

Naik, U. (1997). Visual Order in Cities: A Case Study of Udaipur. Diploma Dissertation, Ahmedabad: CEPT, India.

Panchal, U.H. (1995). Timeless Experience: a study of recreational spaces in Indian Palaces. Diploma Dissertation, Ahmedabad: CEPT, India.

Parikh, M. S. (1992). The Urban Public Realm-A Spatial Manifest of Culture, A study of the Urban Public Realm of Ujjain. Diploma Dissertation. Ahmedabad: CEPT, India.

Samant, S. (1992). Understanding Water and Study of Water Edges: A potential for tourism. Diploma Dissertation. Vallabh Vidyanagar: IED, India.

Samant, S, (2004). Manifestation of the urban public realm at the water edges in India - A case study of the ghats in Ujjain. Cities. 21(3) 233-253.

Sen, R. (2000). Attributes of Place-The urban space in the traditional Indian city of Udaipur, Diploma Dissertation, Ahmedabad: CEPT, India.

Shivanand Swamy, H.M., A. Vyas, and S. Narang. Urban Innovations - Transformation of Surat from Plague to Second Cleanest City in India. Published for the Urban Management Programme for Asia and the Pacific. All India Institute of Local Self Government.

Ulke, H. (1979). The Rath Yara in Puri - Rathas and Rajas: The car festival at Puri, AARP Dec 16.

Verma, S.K. (1998). Reviving Wetlands Issues and Challenges, Himanshu Publications, Udaipur, New Delhi. 


\section{Figures}

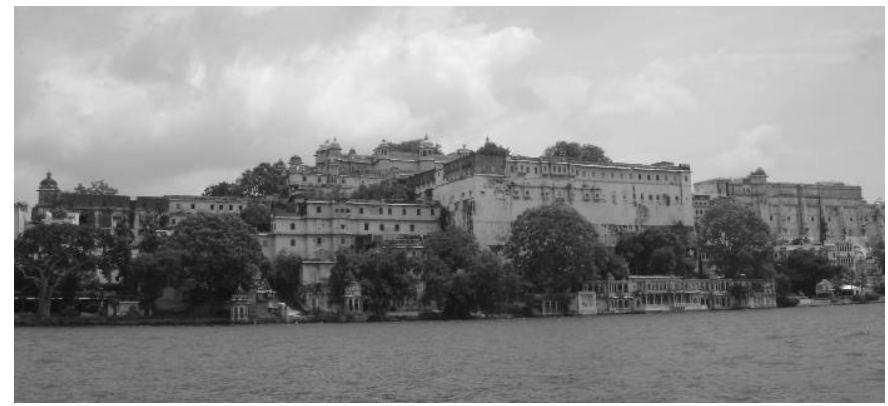

Figure 1. Palace and residential terraces overlooking Lake Pichola

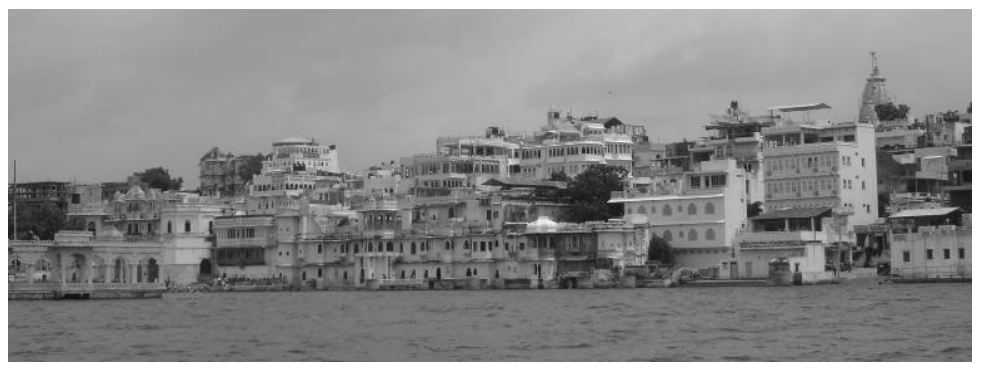

Figure 2. Additive layering of the built form

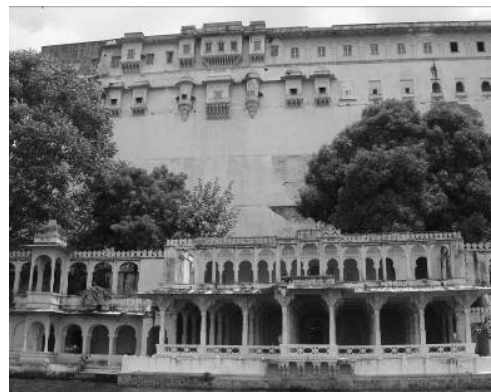

Pavilions along the lake with the palace in the backdrop

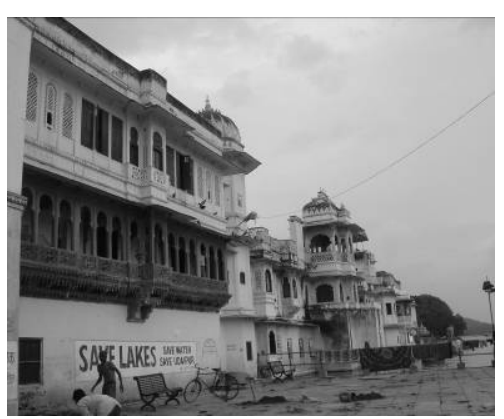

Haveli at Gangaur Ghat

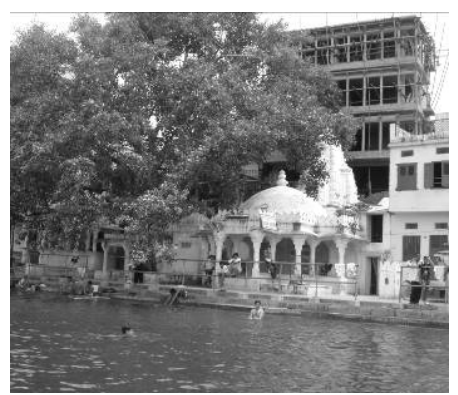

Temples along the lake

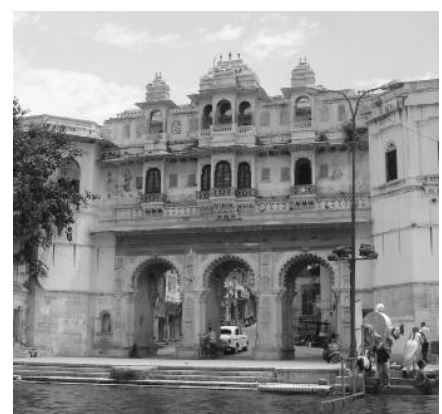

Gangaur Ghat

Figure 3. Lake Façade and its elements 


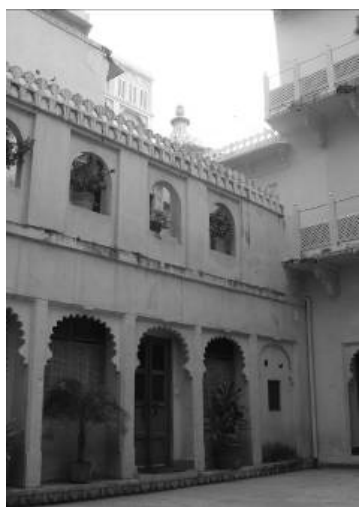

Figure 4. Havelis converted into hotels

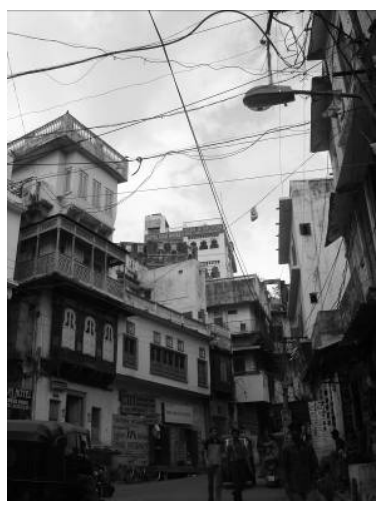

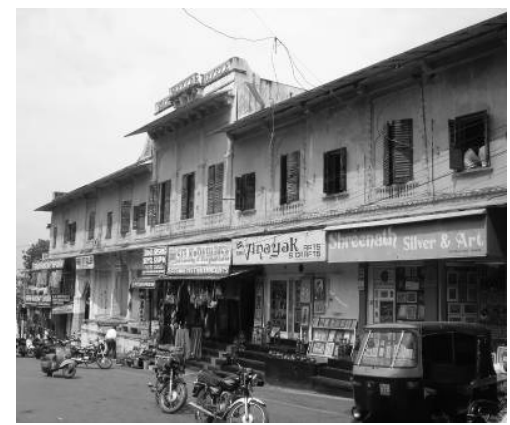

Figure 5. Residences with shops on the ground floor

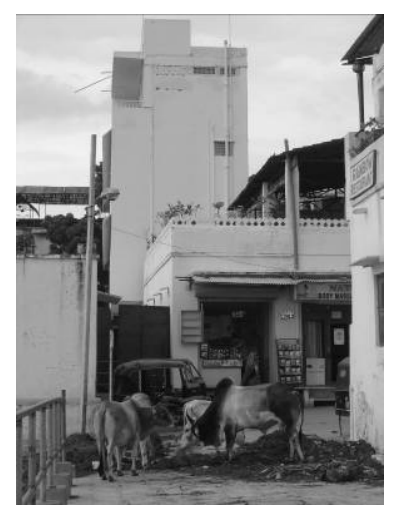

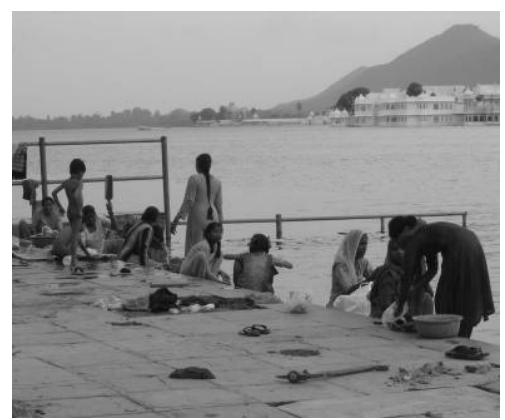

Figure 6. Gangaur Ghat activities

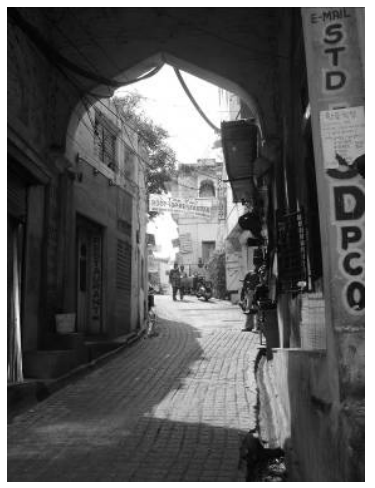

Figure 7. Visual Decay - Hoardings, graffiti, electric poles and open drains
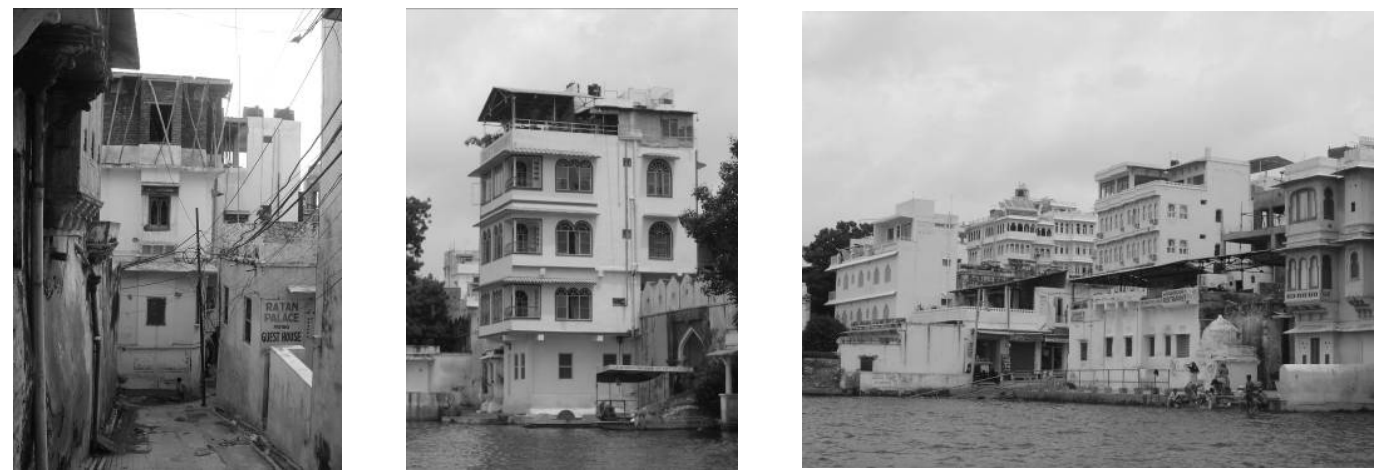

Figure 8. Unsympathetic new insertions
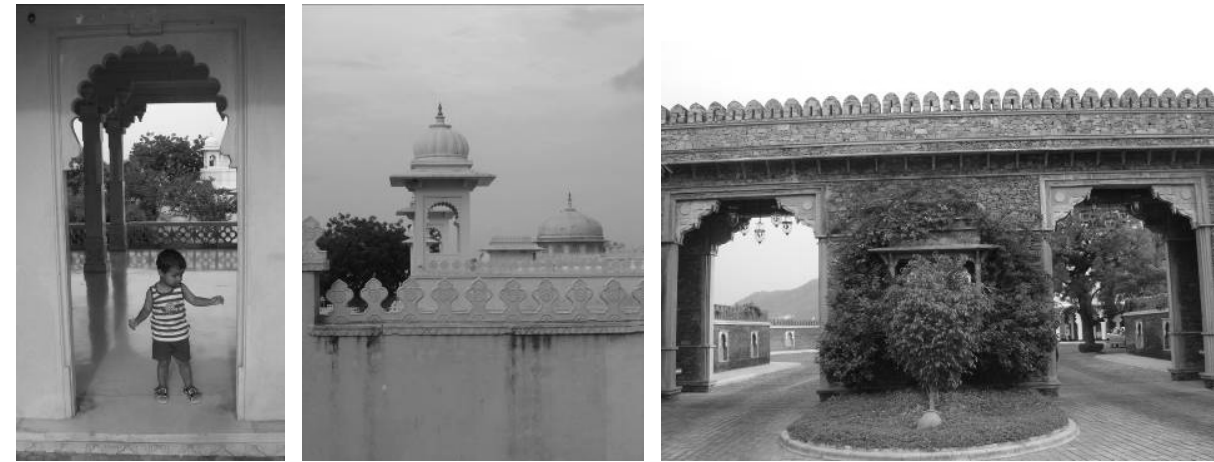

Figure 9. Use of traditional vocabulary in a large scale hotel 